Thorax (1965), 20, 357.

\title{
Innervation of the diaphragm and its practical aspects in surgery
}

\author{
ROBERT SCOT T ${ }^{1}$ \\ From Stobhill General Hospital, Glasgow N.I
}

Older French anatomists speak of the formation of 'nets' by the phrenic nerve within the substance of the diaphragm. Botha (1957) described the course of both phrenic nerves and in particular the posterior diversions of the nerve within the diaphragm. Collis, Satchwell, and Abrams (1954) made a particular study of the crural innervation. Perera and Edwards (1957) noted the formation of neural arcades among the various intramuscular branches of the left phrenic nerve. Merendino, Johnson, Skinner, and Maguire (1956) discussed macroscopic dissections of the diaphragm and correlated these with experimental work and operative findings.

\section{PRESENT STUDY}

Twenty-one human diaphragms were dissected. Four of these only were preserved in a fixative to allow transportation from another hospital.

Particular attention was paid to the distribution of the right phrenic nerve within the muscle of the diaphragm. The nerve was dissected and demonstrated in every case as seen from the thoracic aspect of the diaphragm, and in the description to follow the nerve is depicted as seen from the thoracic side of the diaphragm.

DESCRIPTION The right phrenic nerve reaches the diaphragm at a point 0.5 to $3 \mathrm{~cm}$. lateral to the edge of the inferior vena caval opening and does not, as is generally stated, pass through the caval hiatus. The inferior vena cava opens directly into the sac of fibrous pericardium, whereas the phrenic nerve lies outwith the fibrous pericardium. The main nerve tract divides 0.5 to $4 \mathrm{~cm}$. from the upper surface of the diaphragm into three main divisions and several smaller branches. The latter pass vertically downwards to pierce the central tendon and ramify on the abdominal surface of the diaphragm. From the point of division a few small branches arise which supply the inferior

1 Formerly of the Department of Anatomy, University of Glasgow vena cava, the adjacent fibrous pericardium, and the pericardium overlying the central tendon.

A constant finding is that the main nerve trunk divides into an anterior, a lateral, and a posterior division. In 11 cases the anterior and lateral divisions had a common origin, and in 10 cases they arose as separate divisions. The posterior division is the largest of the three. All divisions quickly enter the substance of the diaphragm and run an intramuscular course between the thoracic and abdominal surfaces (Fig. 1).

The anterior division quickly divides into sternal and anterior branches. The sternal branch loops forward round the antero-lateral border of the pericardium to terminate in the mid-line, where it meets its fellow from the left phrenic nerve. This is a constant finding. The anterior branches of the anterior division supply the diaphragmatic muscle in the antero-medial sector.

The lateral division gives anterior branches which supply the antero-lateral sector to the periphery of the diaphragm, but the main part of this division courses in front of the central tendon and turns posteriorly round its lateral border.

The posterior division has a short course to the posterior border of the central tendon, where it divides into postero-medial and postero-lateral branches. The postero-medial branch supplies the right half of the oesophageal hiatus and the right crus, while the postero-lateral branches arch laterally within the muscle along the posterior edge of the central tendon (Fig. 2). Ganglia were found in two cases on the posterior division branches.

The above description refers to the main divisions of the nerve, but in addition neural arcades were a constant finding among the branches of the nerve. The largest arcade is formed between the lateral branch of the lateral division and the postero-lateral branch of the posterior division around the central tendon. The next most common site is along and through the anterior border of the central tendon (Figs 3, 4, 


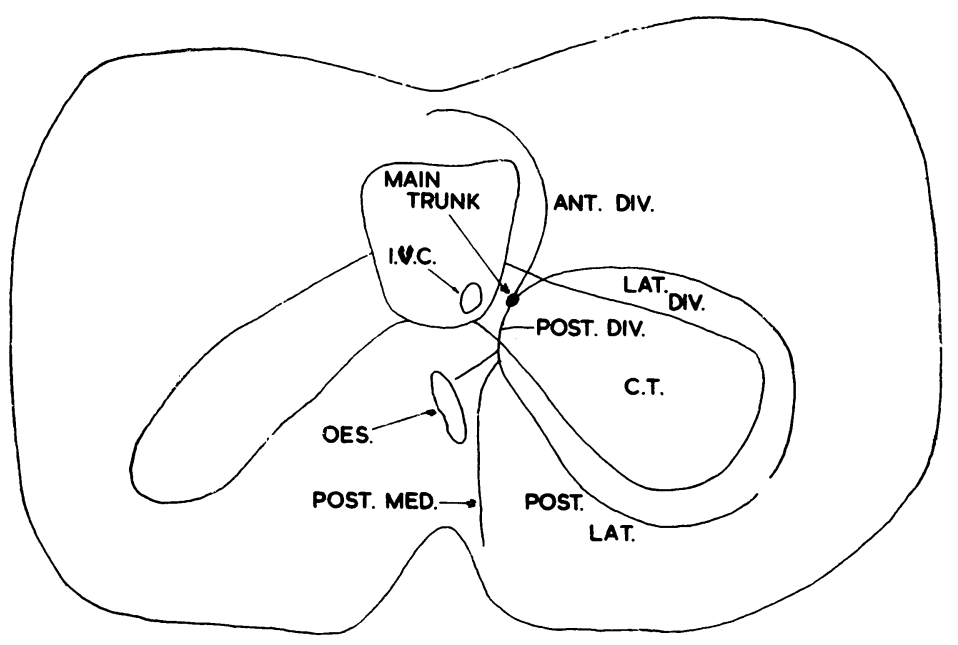

FIG. 1. Diaphragm seen from above showing main divisions of right phrenic nerve.

FIG. 2. Diaphragm seen from above showing main branches of the right nerve.

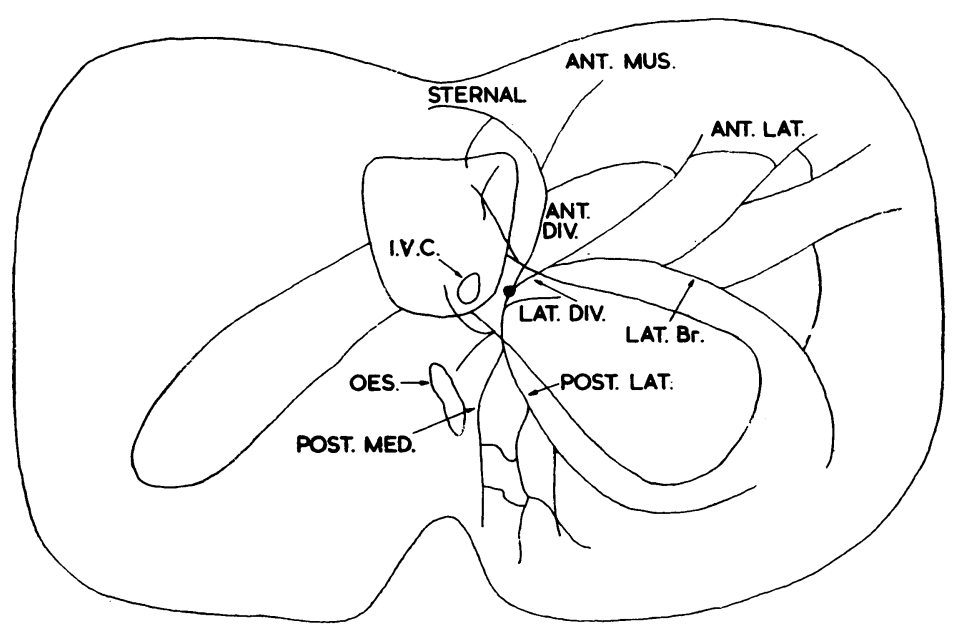

and 5). This arcade is formed by the lateral branch of the lateral division and another branch coming either from the posterior division or from the lateral division.

The left phrenic nerve is a mirror image of the right phrenic nerve with the slight difference that it reaches the diaphragm more anteriorly.

\section{DISCUSSION}

The present study confirms the presence of neural arcades within the various branches of the phrenic nerve and the peculiar innervation of the sling muscle around the oesophagus, as described by Collis. In contradistinction to the findings of Botha, ganglia were noted on the branches of the posterior division of the nerve. Merendino et al.
(1956) direct particular attention to the 'pincer'like distribution of the branches of the nerve around the central tendon (Fig. 1). The present study supports this as being the primary arcade o formed by the nerve. The various arcades within $\tilde{O}$ the distribution of the nerve could be classified as $\underset{\mathrm{N}}{ }$ follows: (1) a large primary arcade between the 0 lateral branch of the lateral division and the postero-lateral branch of the posterior division around the central tendon ; (2) a secondary arcade $\stackrel{\mathcal{\Phi}}{+}$ along and through the anterior third of the central 0 tendon; (3) small arcades between the various branches of the anterior and lateral divisions; and (4) small secondary arcades between the various branches of the posterior division.

From a knowledge of the distribution of the phrenic nerve within the substance of the 


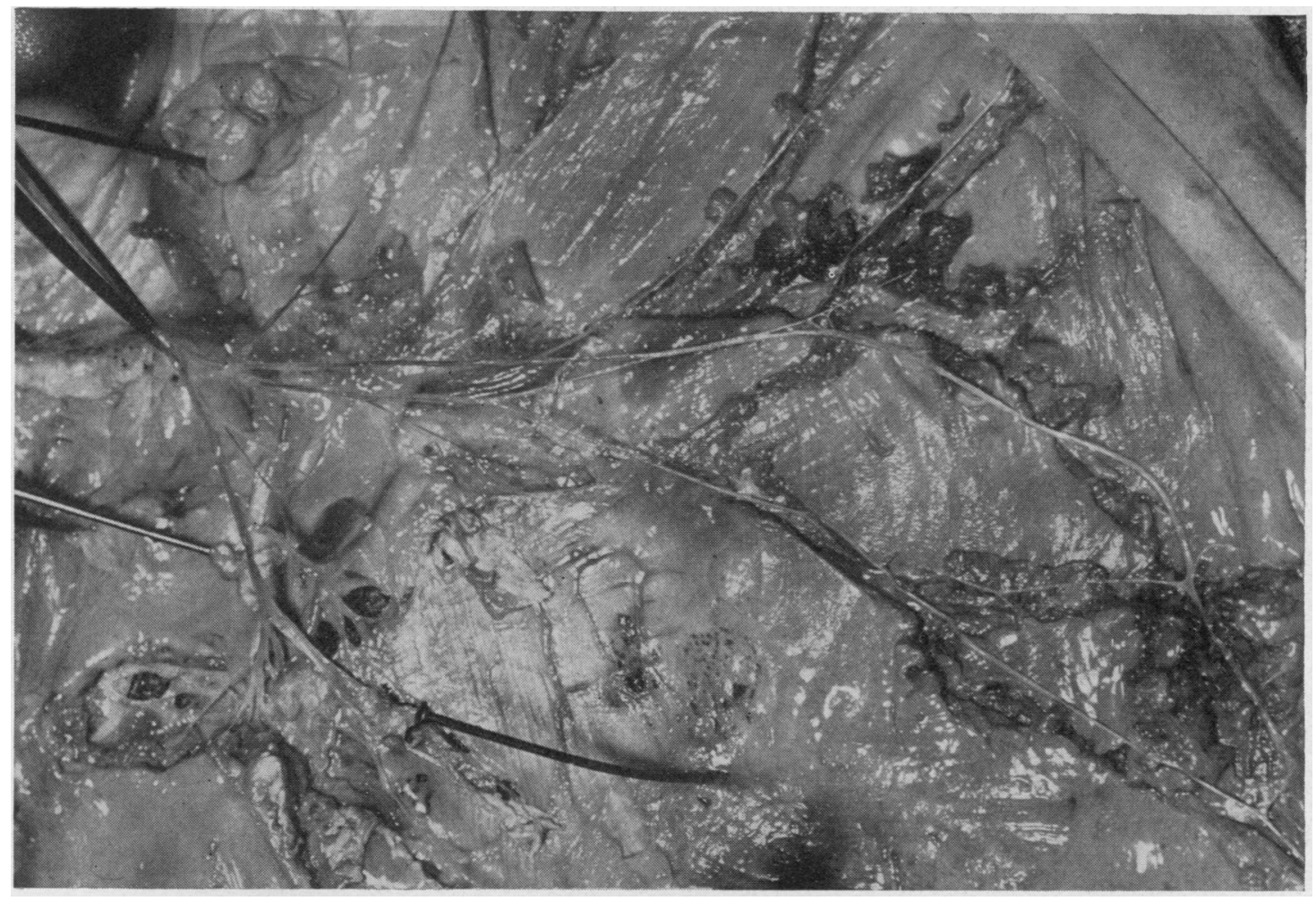

FIG. 3. Main trunk held in forceps. Neural arcade seen in anterior aspect of central tendon.

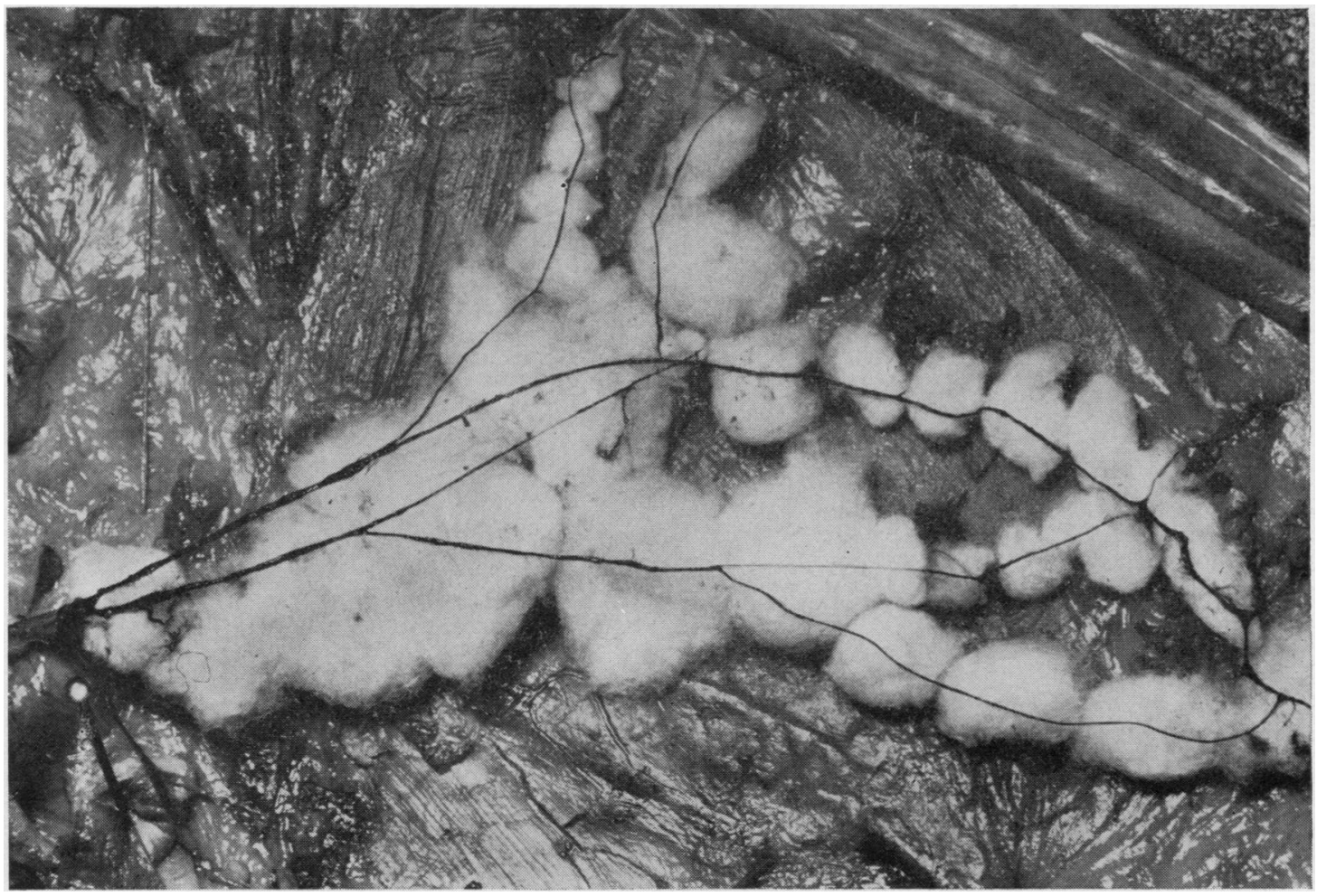

FIG. 4. As Fig. 3. Arcade stained and raised from intramuscular bed. 


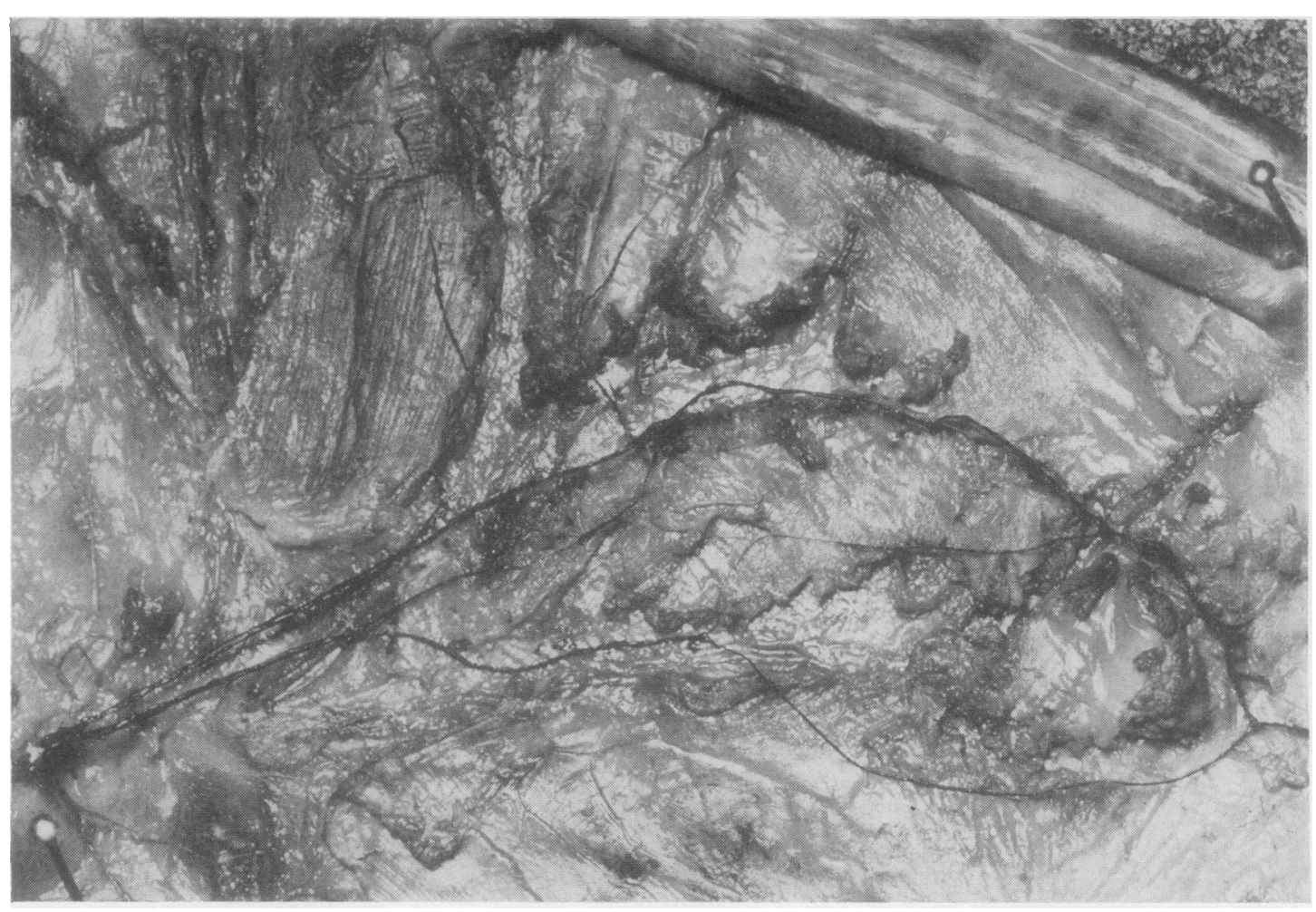

FIG. 5. As Fig. 4. Arcade replaced in intramuscular bed.

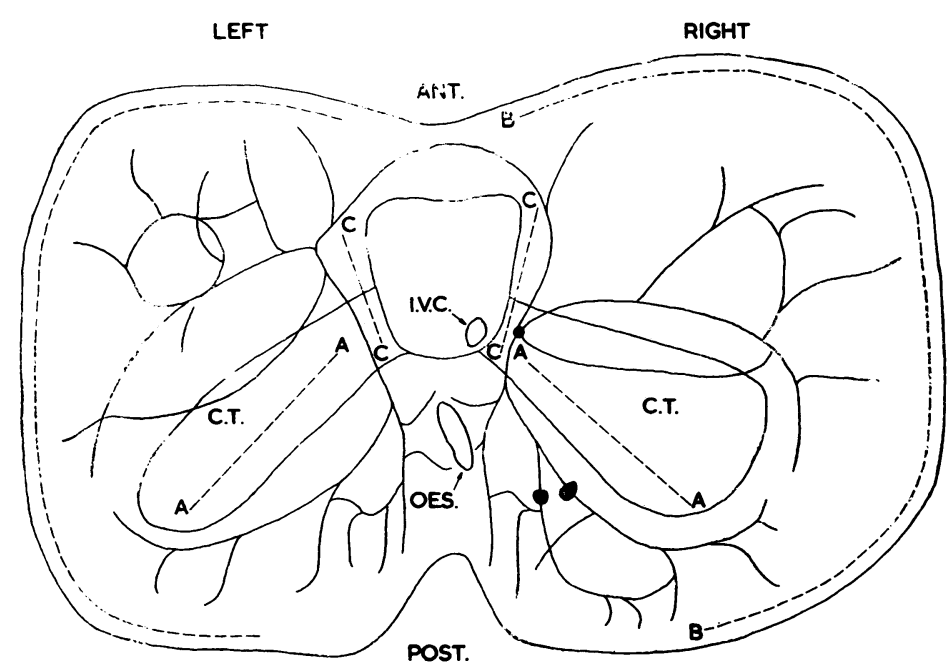

FIG. 6. Composite diagram to show total pattern of innervation of diaphragm. The lines $A A, B B$, and $C C$ represent sites of possible incision. diaphragm, it is possible to direct surgical incisions to areas of the muscle where minimal damage would be inflicted on the nerve. Figure 6 illustrates the total pattern of the distribution of both phrenic nerves within the diaphragmatic substance and the optimal sites for surgical incisions in the light of the present study.

The post-operative pulmonary complications of laparotomy are well known. On the other hand, thoracotomy, even involving extensive pulmonary dissection, is seldom followed by serious pulmonary complication, provided the diaphragm is undisturbed. When, however, a thoraco-abdominal incision is used, providing a synchronous opening of the abdomen and the thorax and associated with a 
varying degree of damage to the diaphragm, the resulting functional disturbance to the structure and to respiration may be considerable. It is therefore important to have a clear understanding of the distribution of the phrenic nerves so that incisions of the diaphragm may be placed in such a way as to avoid damage to its branches. In this way much post-operative morbidity and even mortality may be avoided, especially in the aged, debilitated or acutely ill patient.

\section{SUMMARY}

The existing literature on the phrenic nerve distribution within diaphragmatic substance is reviewed.

The intra-diaphragmatic distribution of 21 phrenic nerves is described.

Neural arcade formation within the various branches of the phrenic nerve is discussed and illustrated along with the ganglia found on the posterior division of the nerve.

Sites suitable for division of the diaphragm are illustrated.

I should like to thank Mr. John Hutchison for his help and encouragement in the preparation of this paper, the Pathology Department at Stobhill Hospital and Law Hospital for the supply of specimens, and Miss S. McLay, of the Photography Department, Stobhill Hospital, for the illustrations. I am deeply indebted to Professor G. M. Wyburn and his staff at the Department of Anatomy, Glasgow University, for their interest and criticism of the paper.

\section{BIBLIOGRAPHY}

Adams, H. D. (1961). Extension of subdiaphragmatic disease processes into the thoracic cavity. Surg. Clin. N. Amer., 41, 847.

Bingham, J. A. W. (1959). Herniation through congenital diaphragmatic defects. Brit. J. Surg., 47, 1.

Botha, G. S. M. (1957). The anatomy of phrenic nerve termination and the motor innervation of the diaphragm. Thorax, 12, 50.

Butler, N., and Claireaux, A. E. (1962). Congenital diaphragmatic. hernia as a cause of perinatal mortality. Lancet, 1, 659 .

Childress, M. E., and Grimes, O. F. (1961). Immediate and remote sequelae in traumatic diaphragmatic hernia. Surg. Gynec. Obstet., 113, 573.

Christensen, P. (1959). Eventration of the diaphragm. Thorax, 14, 311.

Collis, J. L., Satchwell, L. M., and Abrams, L. D. (1954). Nerve supply to the crura of the diaphragm. Ibid, $9,22$.

Kelly, T. D., and Wiley, A.M. (1954). Anatomy of the crura of the diaphragm and the surgery of histua hernia. Ibid., $9,175$.

Landau, B. R., Akert, K and Roberts, T. S. (1962). Studies on the innervation of the diaphragm. J. Comp. Neurol., 119, 1.

Merendino, K. A., Johnson, K. J., Skinner, H. H., and Maguire, R. X. (1956). The intradiaphragmatic distribution of the phrenic nerve, with particular reference to the placement of diaphragmatic incisions and controlled segmental paralysis. Surgery, 39, 189.

Perera, H., and Edwards, F. R. (1957). Intradiaphragmatic course of the left phrenic nerve in relation to diaphragmatic incisions. Lancet, 2, 75 .

Petrovsky, B. V. (1961). The use of diaphragm grafts for plastic operations in thoracic surgery. J. thorac. cardiovasc. Surg., 41, 348.

Rosenblueth,- A., Alanis, J., and Pilar, G. (1961). The accessory motor innervation of the diaphragm. Arch int Physiol., 69, 19.

Walker, W. F., and Attwood, H. D. (1960). The inferior vena cavah opening in the diaphragm. Brit. J. Surg., 48, 86. 